\title{
As campanhas de vacinação contra a poliomielite no Brasil (1960-1990)
}

\author{
Vaccination campaigns against poliomyelitis in Brazil (1960-1990)
}

Dilene Raimundo do Nascimento ${ }^{1}$

\begin{abstract}
This article discusses the vaccination campaigns against poliomyelitis in Brazil. It examines issues that have shaped the politics of disease control at the interface with the history of science and technology with regard to the discovery of vaccines, the development of laboratory techniques for diagnosis and surveillance of new procedures, and history of public health policies in relation to decision making and implementation of control and eradication of disease. The aim is also to demonstrate that in addition to the technologies available, it was necessary some negotiation and political will to achieve the control and eradication of the disease in the country. The main sources used were scientific articles, oral testimonies, official documents and newspaper articles.
\end{abstract}

Key words Vaccination, Polio, Health policy, History, Brazil
Resumo Este artigo pretende discutir as campanhas de vacinação contra a poliomielite no Brasil. Examina as questões que formataram a politica de controle da doença, na interface com a história da ciência e da tecnologia, no que diz respeito à descoberta das vacinas, ao desenvolvimento de técnicas laboratoriais de diagnóstico e novos procedimentos de vigilância epidemiológica, e com a história das políticas de saúde pública, no que se refere à decisão e implementação do controle e posterior erradicação da doença. Pretende ainda demonstrar que, para além das tecnologias disponíveis, foram necessárias negociação e vontade política para se alcançar o controle e posterior erradicação da doença no país. As fontes utilizadas foram, principalmente, artigos científicos, depoimentos orais, documentos oficiais e matérias jornalísticas.

Palavras-chave Vacinação, Poliomielite, Política de saúde, História, Brasil
${ }^{1}$ Casa de Oswaldo Cruz, Fundação Oswaldo Cruz. Av. Brasil 4.036, sala 408, Manguinhos. 21040-361 Rio de Janeiro RJ.

dilene@coc.fiocruz.br 


\section{Introdução}

Com o aumento das coberturas de vacinação e a viabilidade técnica para a erradicação no que diz respeito à poliomielite, a Comissão Internacional para a Certificação da Erradicação da Poliomielite (CICEP), reunida em Washington em agosto de 1994, declarou interrompida a transmissão do poliovírus selvagem nas Américas. Estava erradicada a poliomielite no continente americano.

A região das Américas foi a primeira a atingir a erradicação do vírus selvagem da poliomielite, e a estratégia utilizada para alcançar essa meta foi adotada como modelo para outras regiões do mundo, numa perspectiva de erradicação global da doença.

Ao comentar a erradicação da poliomielite nas Américas, em entrevista concedida à Casa de Oswaldo Cruz, no ano de 2000, para o projeto História da Poliomielite e de sua Erradicação, Ciro de Quadros" afirmava que "a erradicação da pólio não foi, em si, um objetivo único”, mas um dos objetivos. O segundo foi reforçar os programas nacionais de vacinas e o terceiro, mobilizar a sociedade, isto é, mudar a mentalidade dos governos e da população em relação às vacinas. $\mathrm{Na}$ sua avaliação, a erradicação já foi alcançada; o programa de vacinação saiu fortalecido e a mobilização política e social a favor da saúde também avançou bastante. O êxito da erradicação da poliomielite, seguido à erradicação da varíola, ratificou a credibilidade da vacina.

Contudo, na primeira metade do século XX, num contexto em que a bacteriologia se afirmava no campo científico, a poliomielite ainda era um grande desafio para a biomedicina. Apesar de o poliovírus ter sido identificado pela primeira vez em 1908, por Karl Landsteiner e Erwin Popper, seu modo de transmissão permaneceu um mistério por algumas décadas, objeto de pesquisas e controvérsias entre médicos e cientistas no sentido de chegarem a um modelo científico explicativo da doença ${ }^{2}$. Somente na década de 1940, com o avanço da virologia e o uso do microscópio eletrônico, foi esclarecida a forma de transmissão da poliomielite: ficou evidenciado que o poliovírus se multiplicava no trato gastrointestinal e sua transmissão ocorria pela via fecal-oral, isto é, por meio da água ou produtos contaminados por fezes e ingeridos pela boca.

Ainda na década de 1940, mais exatamente em 1949, John Enders, Frederick Robbins e Thomas Weller desenvolveram uma técnica de cultivo em tecidos ${ }^{3}$. A possibilidade de uma vacina eficaz contra a poliomielite se tornou concreta com essa nova técnica de cultura em tecidos, e vários laboratórios trabalharam para conseguir esse feito ${ }^{4-6}$. Salk e sua equipe foram os primeiros a apresentarem resultados, e sua vacina injetável, com vírus inativado, obteve autorização de uso pelos Estados Unidos em 1955. Sabin, a seguir, chegou à vacina com vírus atenuado e de aplicação oral, recebendo autorização de uso em 1960. Assim, chegou-se à descoberta de duas vacinas contra a poliomielite - a vacina Salk e a vacina Sabin, ambas de laboratórios americanos.

Com duas vacinas disponíveis e consideradas eficazes na prevenção da poliomielite ${ }^{7,8}$, somando-se ao desenvolvimento de técnicas laboratoriais para diagnóstico da doença ${ }^{9}$ e procedimentos de vigilância epidemiológica ${ }^{10}$, foi possível formatar estratégias de vacinação para o controle da doença.

No caso específico da erradicação da poliomielite, proposta pela Organização Pan-Americana da Saúde (Opas) em 1985, ficou patente que a cooperação internacional foi um instrumento da mais alta relevância para desenvolver as capacidades nacionais nos países da América Latina. A Opas, o Rotary Internacional e o United Nations Children Fund (Unicef) atuaram de forma decisiva para a implementação das políticas de imunização nos países, num trabalho cooperativo com cada realidade nacional. Exceção feita a Cuba, que, vale lembrar aqui, implementou a primeira campanha de vacinação em massa contra a poliomielite em 1962, com a estratégia de dias nacionais de vacinação, e logo alcançou a eliminação da pólio no país.

Ao se analisar o processo de erradicação da poliomielite, percebem-se o desenvolvimento e a legitimação das políticas de saúde nacionais e internacionais, o processo de incorporação de tecnologias e as práticas e construções discursivas da medicina com vistas ao controle da doença, em que estão envolvidos sociedade, Estado, instituições, mercado e organismos internacionais.

As campanhas de vacinação contra a poliomielite no Brasil são o objeto deste artigo. Essa análise é desenvolvida na interface com a história da ciência e da tecnologia, no que diz respeito às vacinas, às técnicas laboratoriais de diagnóstico e novos procedimentos de vigilância epidemiológica, e com a história das políticas de saúde pública, no que se refere à decisão e implementação do controle e posterior erradicação da doença. Pretende-se ainda demonstrar que, para além das tecnologias disponíveis, foram necessárias a negociação e vontade política para se alcançar o controle e posterior erradicação da doença no país. 


\section{As vacinas contra a poliomielite chegam ao Brasil}

No Brasil, a vacina Salk passou a ser utilizada desde 1955, por médicos pediatras e em vacinações de amplitude reduzida, promovidas pelas secretarias de saúde municipais e estaduais, principalmente no Rio de Janeiro e em São Paulo.

Com o advento da vacina Sabin e sua autorização de uso em 1960 pelos EUA, em razão de ensaios de campo bem-sucedidos, realizados em Cingapura, em 1957, e na URSS, nos anos seguintes $^{11}$, instaurou-se um debate sobre qual das duas seria mais eficaz e mais adequada para aplicação em campanhas de prevenção. Da mesma forma, um dos assuntos palpitantes da V Conferência Internacional da Poliomielite, realizada em Copenhague entre os dias 26 e 28 de julho de 1960, foi a disputa entre as vacinas Salk e Sabin ${ }^{12}$.

A discussão aqui no Brasil sobre os dois tipos de vacina ocupou vários fóruns médicos, principalmente a Sociedade Brasileira de Pediatria e a Sociedade Brasileira de Higiene. Em 1961, o ministro da saúde, Edward Catete Pinheiro, criou uma comissão composta por médicos de prestígio para produzir um parecer sobre as vantagens e desvantagens de uma e de outra vacina antipólio. Compuseram a comissão: Joaquim Travassos, diretor do Instituto Oswaldo Cruz; José Martinho da Rocha, catedrático de pediatria da Universidade do Brasil; Paulo de Góes, catedrático de microbiologia também da Universidade do Brasil; Oswaldo Pinheiro de Campos, ortopedista; Madureira Pará, virologista; Bichat de Almeida Rodrigues, diretor do Departamento Nacional de Saúde; e Álvaro Aguiar, presidente da Sociedade Brasileira de Pediatria. A comissão se posicionou favorável ao uso da vacina Sabin, justificando seu baixo custo, sua inocuidade, a maior facilidade de aplicação por ser via oral, seu efeito protetor mais prolongado e sua capacidade de multiplicação no sistema digestivo, possibilitando a eliminação do vírus vacinal no ambiente ${ }^{13}$.

Mediante o parecer da comissão, o Ministério da Saúde adotou, oficialmente, a vacina oral trivalente de vírus vivo atenuado - a vacina Sabin - e iniciou, em julho de 1961, campanhas de vacinação da população infantil nas cidades de Santo André, São Bernardo e São Caetano, no estado de São Paulo, com a expectativa de vacinar 25 mil crianças. No Rio de Janeiro, após uma experiência piloto no Instituto Fernandes Figueira (hoje a unidade materno-infantil da Fundação Oswaldo Cruz), onde foram vacinados os filhos dos funcionários na faixa etária de quatro meses a seis anos, ocorreu uma vacinação em massa, de 28 de agosto a 2 de setembro, em Petrópolis. Essa vacinação, cuja expectativa era vacinar 15 mil crianças, recebeu ampla cobertura da imprensa, noticiada como a inauguração oficial da "Campanha Nacional de Vacinação Oral contra a Poliomielite no Brasil"14.

$\mathrm{O}$ governo federal deu seguimento às campanhas de vacinação e importou três milhões de doses de vacina oral para realizar uma grande campanha na cidade do Rio de Janeiro, entre os dias 16 e 21 de outubro de 1961, e por essa iniciativa recebeu moções de apoio de várias associações médicas do país, com declarações favoráveis veiculadas pelos principais jornais, na épo$\mathrm{ca}^{15}$. Com o lema "Uma gota, duas doses: uma criança sadia, livre da paralisia", a primeira vacinação contra a poliomielite de grande amplitude foi levada a efeito em 278 postos instalados por todos os bairros cariocas e contou com a colaboração de 2.500 voluntários. Do dia 16 ao dia 21 de outubro de 1961, a expectativa era vacinar 500 mil crianças, entre quatro e seis anos de idade, mesmo aquelas que haviam recebido a vacina Salk. Os jornais deram cobertura diária a essa campanha, avaliando-a como bem-sucedida e manifestando a necessidade de a campanha ocorrer nacionalmente ${ }^{16}$.

A campanha se ampliou para várias capitais brasileiras, uma a cada vez, com vacinas distribuídas pelo Ministério da Saúde. Entretanto, essas campanhas se caracterizaram mais pela descontinuidade, em face de problemas de suprimento e distribuição das vacinas, do que pelo aumento de cobertura vacinal. A falta de um registro sistemático da incidência da doença, apesar de constar como de notificação obrigatória desde o Decreto ${ }^{\circ} 16.300$, de 1923, impossibilitou uma avaliação mais precisa do impacto das vacinações na ocorrência da doença.

No início da década de 1960, a Fiocruz começou a pesquisar tecnologias que foram fundamentais para o controle da poliomielite. O Instituto Oswaldo Cruz desenvolveu técnicas cada vez mais sensíveis e rápidas de diagnóstico do poliovírus, assim como o aperfeiçoamento da formulação da vacina antipólio oral ${ }^{9}$.

No cenário internacional, o conceito de vigilância já circulava nos meios da saúde pública. $\mathrm{O}$ conceito "A observação contínua da distribuição e tendências da incidência de doenças mediante a coleta sistemática" foi proposto inicialmente por Alexander Langmuir, epidemiologista americano, e aperfeiçoado por Karel Raska, epidemiologista tcheco, no início da década de $1960^{10}$. Esse conceito, 
que se traduz em ação, foi introduzido no Brasil pela Fundação de Serviços Especiais de Saúde Pública (FSESP) ao criar, em 1968, o Centro de Investigações Epidemiológicas, cuja preocupação principal eram as doenças evitáveis por vacinação ${ }^{17}$.

Com vacinas disponíveis e novas tecnologias no que diz respeito à poliomielite, o governo federal decidiu estabelecer um plano de controle da doença, no início da década de 1970.

\section{Plano Nacional de Controle da Poliomielite}

Em face de ocorrência de repetidos surtos da poliomielite em várias cidades brasileiras, o Ministério da Saúde instituiu o Plano Nacional de Controle da Poliomielite, em 1971. João Baptista Risi Jr. ${ }^{17}$, coordenador desse plano, acreditou na sua exequibilidade por ser uma estratégia nacional, com definição de normas técnicas para todos os procedimentos e para o abastecimento da vacina. As experiências anteriores de campanha contra a pólio, desde 1961, como foi dito, sofreram muita descontinuidade. Risi Jr. ${ }^{17}$, em entrevista concedida à Casa de Oswaldo Cruz, no ano de 2000, para o projeto História da Poliomielite e de sua Erradicação, disse que a história da pólio no Brasil, depois da vacina, era mais ou menos essa: você tinha uma epidemia da doença e em seguida uma epidemia de vacinação, pois a aplicação da vacina chegava sempre atrasada, isto é, quando a epidemia já estava em declínio.

As crianças dos segmentos mais favorecidos da população, que são as mais suscetíveis à forma paralítica por não terem desde cedo contato com o vírus ${ }^{18}$, eram vacinadas por seus pediatras. A poliomielite passou a incidir basicamente nas classes menos favorecidas da população, causando um impacto social menor, e talvez por isso não se traduzisse na organização de campanhas eficientes de vacinação. Soma-se aí a dificuldade decorrente do tamanho territorial e da diversidade existente no país, requerendo grandes quantidades de vacina e uma estrutura de serviços de saúde que, na época, eram insuficientes.

O Plano Nacional de Controle da Poliomielite foi a primeira tentativa organizada nacionalmente de controlar a pólio no Brasil, e sua implementação iniciou-se com um projeto piloto realizado no estado do Espírito Santo. A intenção era estudar a resposta sorológica à vacina e introduzir a metodologia de campanhas estaduais realizadas em um só dia ${ }^{19}$.

O suprimento de vacinas foi assegurado pelo governo federal, e o Plano Nacional de Controle da Poliomielite adotou a estratégia de vacinação em massa, em um só dia, nas zonas urbanas, compreendendo três etapas anuais de vacinação do grupo etário de três meses a quatro anos de idade, realizadas em períodos distintos nos diversos estados. A execução ficaria a cargo dos estados e municípios, e o Ministério da Saúde se comprometia também com a supervisão técnica, desempenhada por um profissional da área de epidemiologia e um educador.

Contudo, em 1971 ocorreu somente a experiência do Espírito Santo, e em 1972 e 1973 o plano foi executado em 14 estados. O impacto dessas campanhas na incidência da doença foi muito difícil de medir, como reconhece Risi Jr. ${ }^{17}$, porque não se tinham dados epidemiológicos prévios no país.

Em 1973, foi criado o Programa Nacional de Imunizações (PNI), que incorporou o controle da poliomielite e introduziu a multivacinação, incluindo principalmente a vacina do sarampo, ainda com estratégia de campanhas. O PNI foi uma das iniciativas da gestão do ministro Mário Machado Lemos, que se caracterizou pela elaboração de grandes planos para a saúde. O propósito do PNI foi estimular e expandir a utilização de agentes imunizantes no país, em decorrência do Plano Decenal de Saúde para as Américas, discutido na $3^{\text {a }}$ Reunião de Ministros de Saúde das Américas, realizada em 1972, no Chile, que incluía a proposta de redução da morbidade e mortalidade por doenças evitáveis por imunização.

Com o governo Geisel, iniciado em 1974, assumiu Paulo de Almeida Machado como ministro da saúde e, com ele, um grupo de técnicos de São Paulo com forte influência da Faculdade de Saúde Pública da Universidade de São Paulo (USP), que defendia tenazmente a atuação do centro de saúde, as ações de rotina e a educação sanitária; com isso, foi abandonada a estratégia de campanha.

A suspensão das campanhas de vacinação resultou, por um lado, na diminuição da cobertura vacinal, até porque não havia serviços de saúde suficientes no país para a vacinação de rotina; por outro, ganhou-se na normalização técnica no que diz respeito à vacinação, na questão da conservação da vacina, na rede de frio e, principalmente, no que diz respeito à vigilância epidemiológica. Em 1975, estabeleceram-se as atividades de vigilância, com a implantação do Sistema Nacional de Vigilância Epidemiológica, fundamental para qualquer plano de controle, que incluíam normas técnicas para a confirmação clínica e laboratorial dos casos de poliomielite e 
para a investigação epidemiológica em âmbito nacional, que já estava sendo gestada desde a década de 1960 .

O general João Baptista Figueiredo assumiu a Presidência da República, em fins de 1978, com um processo de abertura democrática iniciado. O governo a essa altura estava bastante interessado em implementar políticas sociais para sua legitimação. Ainda no primeiro ano de governo Figueiredo, foi nomeado como ministro da saúde Waldir Arcoverde, um sanitarista com a experiência do Rio Grande do Sul, que nessa época era um modelo de excelência no Brasil em termos de saúde pública. Um dos pontos de sua plataforma de gestão era desenvolver um programa de vacinação.

Arcoverde convidou Mozart de Abreu Lima para ocupar o cargo de secretário geral do ministério e compôs seu ministério com técnicos oriundos da Superintendência de Desenvolvimento do Nordeste (Sudene), que, segundo Lima, traziam "a força da inovação dos processos administrativos, sobretudo do planejamento", técnicos do RS que nacionalmente tinham a experiência mais avançada em termos de vigilância epidemiológica e técnicos da FSESP que possuíam grande conhecimento da realidade brasileira e de estratégias de controle de doenças, incluídas as preveníveis por imunização ${ }^{20}$.

Essa nova equipe do Ministério da Saúde se deparou, na sua chegada, com importante epidemia de poliomielite, no Paraná e em Santa Catarina, estados esses que mantinham um nível de vacinação bastante razoável. O secretário de saúde do Paraná, Oscar Alves, foi para a televisão denunciar a existência da epidemia, atribuindo-a ao descaso do governo federal, o que produziu uma grande repercussão nacional, em fins de 1979 e início de 1980.

Esses elementos criaram uma configuração favorável para se decidir pelo enfrentamento da poliomielite no Brasil. A estratégia básica foi definida nos primeiros dias do mês de janeiro de 1980: vacinação maciça em período muito curto de tempo em todo o território nacional ${ }^{21}$.

O Ministério da Saúde convidou Albert Sabin, o criador da vacina oral, com experiência de sua aplicação em massa e, reconhecidamente, uma autoridade internacional no assunto, para assessorar a equipe no aprimoramento do modelo de intervenção, em janeiro de 1980. Sabin propôs uma pesquisa sobre prevalência de sequelas em escolares, abrangendo todo o país, com a perspectiva de examinar 1,4 milhão de crianças, para estimar a magnitude da doença no território nacional e, a partir daí, definir as ações de controle da pólio.

Essa proposta de Sabin criou uma séria divergência entre o cientista e o ministro da saúde, que defendia uma ação imediata. A pesquisa proposta por Sabin demandava recursos e tempo, naquele momento inaceitável, pois postergaria uma intervenção que se requeria urgente ${ }^{22}$. Sabin rompeu com a equipe do Ministério da Saúde e criticou fortemente o ministro Arcoverde, pela imprensa. Em carta ao presidente da República, Sabin defendia a exatidão dos dados estatísticos considerando que, assim como em operações militares, informes inexatos sobre inimigos podem levar a desastres, o mesmo ocorre quando se trata de combater uma doença epidêmica ${ }^{23}$.

A imprensa se ocupou com essa polêmica ao longo do mês de março. A opinião pública nacional e internacional fez coro com Sabin, com duras críticas ao ministério. Esse conflito chegou a ameaçar a permanência de Arcoverde no ministério. Porém, por decisão do presidente da República, segundo Lima ${ }^{20}$, o ministro mantevese no cargo e considerou que o caso Sabin alertou o povo e contribuiu para criar uma consciência social sobre o problema da poliomielite paralítica e sobre a necessidade da vacinação em massa ${ }^{24}$.

A proposta do ministério também encontrou resistências entre os sanitaristas que defendiam a atenção primária à saúde como a política adequada para melhoria integral da qualidade de vida das populações e consideravam a estratégia de campanha prejudicial à conscientização e educação da população para as ações de saúde de rotina ${ }^{17}$. Risi Jr. ${ }^{17}$ ressalta ainda que a Organização Mundial da Saúde (OMS), que havia promovido a conferência internacional na cidade de Alma-Ata, também não apoiou a ideia de "dia nacional". Em que pese a experiência bem-sucedida, na década de 1960, de dias nacionais de vacinação em Cuba, em fins da década de 1970 e início da de 1980, havia uma forte defesa pela Atenção Primária à Saúde, resultado da conferência de Alma-Ata.

Contudo, todos os recursos e apoios possíveis foram mobilizados para a realização dessa campanha de vacinação; desde o nível central, com o apoio de todos os órgãos ministeriais, até clubes de serviço e grupos comunitários em nível local. Assim, nos dias 14 de junho e 16 de agosto de 1980 se realizaram respectivamente a primeira e a segunda etapas da vacinação contra a poliomielite no país, para vacinar todas as crianças de zero a cinco anos de idade, independentemente de vacinação prévia, em um só dia, em todo o território nacional. 


\section{A experiência do Dia Nacional de Vacinação}

O Dia de Vacinação foi um movimento de massa no país, porque nós vacinamos vinte milhões de crianças. [...] As demandas, as filas enormes, a população acorreu em massa, foi uma festa da sociedade brasileira ${ }^{20}$.

Para se chegar a essa "festa da sociedade brasileira" houve um trabalho "monumental", tanto para montar a infraestrutura de armazenagem, controle de qualidade e distribuição das vacinas e demais insumos necessários, como para negociar com os outros ministérios - principalmente o de Planejamento, para liberação de recursos financeiros, e o de Relações Exteriores, para importação das vacinas - e com os estados ${ }^{20}$.

A essa altura, as características epidemiológicas da poliomielite, não só no tempo e no espaço mas também em relação a outras importantes variáveis, como idade, estado vacinal prévio, tipo de poliovírus isolado, município de ocorrência e informações relacionadas com a presença de sequelas, já estavam estudadas. Viu-se que a poliomielite incidia mais nas crianças do grupo etário de 0-4 anos, com predominância no de seis meses a dois anos, não vacinadas, que viviam em zonas urbanas, e era causada principalmente pelo pólio vírus do tipo $1^{17}$.

Segundo Rocha ${ }^{25}$, educadora do Ministério da Saúde, a decisão da vacinação em massa não foi tranquila. Do momento da decisão pela vacinação até efetivamente realizar a vacinação, houve uma discussão que se deu dentro da Secretaria Nacional de Atenção Básica à Saúde (SNABS) e "teve muita briga, muita briga mesmo"; ela menciona em especial as divergências entre Sabin e a equipe do Ministério da Saúde.

Iniciou-se um processo intenso de negociação política entre o Ministério da Saúde e os estados, no nível de governadores e secretários de saúde. O ministro da saúde viajou para todos os estados para conseguir que os governadores priorizassem a campanha contra a poliomielite ${ }^{20}$. Era imprescindível que os estados se comprometessem com essa estratégia de Dias Nacionais de Vacinação, porque a execução estaria ao seu encargo, o Ministério da Saúde entraria com os recursos materiais necessários, inclusive o suprimento de vacinas, e o apoio logístico. Cristina Rocha ${ }^{25}$ relata: quando decidiram: vai-se fazer a vacinação, a gente entrou de cheio, tanto para trabalhar a questão da comunicação, como para trabalhar a estruturação das campanhas nos estados. E essa foi a grande tarefa nossa.
Os técnicos iam em dupla - um epidemiologista e um educador - para os estados para organizar grupos responsáveis pelos recursos humanos, pela logística e pela orientação técnica. Participavam não só funcionários das secretarias como de outras instituições. Outra tarefa dos técnicos era convencer da viabilidade dessa vacinação, porque esse era o grande questionamento. Todo mundo achava que era uma loucura fazer isso e realmente saíamos pelos estados para defender essa idéia ${ }^{25}$.

Esse trabalho de convencimento junto aos estados resultou no engajamento de todos, com maior ou menor aderência, ao projeto da campanha contra a poliomielite. Todos os técnicos do ministério estavam bem preparados e tinham argumentos bem fundamentados para defender o projeto. Segundo Cristina Rocha, havia muito apoio político da Presidência da República ao trabalho dos técnicos nos estados, e o preparo dos técnicos foi vencendo as resistências:

De uma maneira geral, era assim: a gente chegava, tinha a equipe da secretaria já articulada. Quer dizer, geralmente o nosso contato era com a vigilância epidemiológica, ela já tinha articulado alguém da educação e saúde, alguém da comunicação social, alguém da área de logística, já tinha convocado o pessoal da Superintendência de Campanhas (SUCAM) daquele estado, já tinha convocado o pessoal da Fundação SESP. Aí vinha a Secretaria de Educação, a Secretaria de Governo e fazia-se um grande fórum para colocar a idéia da estratégia e dali se formavam grupos ${ }^{25}$.

Esses grupos eram multiplicadores para executar o trabalho nos municípios, e os técnicos do ministério passavam a monitorar essa tarefa a ser realizada pelos grupos, enquanto levavam a proposta para outro estado. As resistências nos estados foram muitas. Contudo, segundo Cristina Rocha ${ }^{25}$, o preparo dos técnicos do Ministério da Saúde era grande, resultado de profundas discussões no âmbito do ministério:

Nós ficamos assim experts em pólio, na doença e tudo mais. E todo mundo trabalhava em conjunto. Não tinha: "isso é do educador". Não, a gente ia para as discussões em conjunto e tinha solidez para argumentar e para discutir. E a gente tinha assim muito apoio, apoio político da época. A gente chegava no estado e ia falar com o governo, com todo apoio, não pedia audiência, a audiência já estava marcada. Então, tinha toda essa coisa da estruturação política ${ }^{25}$.

Porém, mesmo com o processo de abertura política engendrado no Governo Geisel e levado à prática no Governo Figueiredo, ainda estávamos 
em um regime de ditadura militar. Nesse sentido, Cristina Rocha é explícita na sua avaliação de que a despeito da negociação política com os estados para adesão ao projeto, em último caso se faria valer o sistema ditatorial vigente no país:

Havia resistências, mas, no final das contas, estado algum não ia fazer, porque se dissesse isso ia ter alguma forma de chegar lá e dizer que ele tinha que fazer. Porque era uma coisa decidida. A gente estava bem preparado, pensou-se em tudo tecnicamente, mas tinha essa decisão ${ }^{25}$.

Quanto aos recursos necessários para a execução da proposta, Mozart Lima ${ }^{20}$ relata que houve apoio irrestrito do presidente da República, com trânsito livre na Secretaria do Planejamento, que ficou inteiramente à disposição para tratar isso com a velocidade que fosse necessária ao processo. Houve um remanejamento de recursos dos outros ministérios para o Ministério da Saúde. Claro que houve o trabalho de ir ao Ministério do Planejamento para explicar o projeto aos seus lideres [...] explicar todo o processo, explicar a viabilidade dele etc. e, a partir daí, com a decisão presidencial tomada, ele foi franqueado a uma atuação sem limitações. Mozart Lima continua seu relato:

Outro ponto estratégico era o Ministério das Relações Exteriores. Que é o quê? Franquear as negociações dos estados, onde tinham empresas dos países. Porque tinham empresas produtoras das vacinas, do próprio estado ou privadas, e era necessária uma ação do governo desses países para facilitar de todos os modos possíveis a produção, [...] e também franquear o processo de controle de qualidade que tinha que ser feito pari passu da produção. Nós não podíamos esperar o término da produção para depois analisar a vacina. Ou seja, cuidar do acesso ao processo produtivo, via Organização Mundial da Saúde, para que tivéssemos a certeza da qualidade dessa vacina, já que teríamos pouquíssimo tempo para testá-las. Então isso foi trabalho do Ministério das Relações Exteriores ${ }^{20}$.

Assim, nos dias 14 de junho e 16 de agosto de 1980 se realizaram respectivamente a primeira e a segunda etapas da vacinação contra a poliomielite no país, para vacinar todas as crianças de zero a cinco anos de idade, independentemente de vacinação prévia, em um só dia, em todo o território nacional.

Fica a pergunta: como calcularam a quantidade de vacinas necessária à cobertura de todas as crianças brasileiras menores de cinco anos? Mozart Lima ${ }^{20}$ nos esclarece que estimaram em vinte milhões o total de crianças e que compraram dois terços a mais de vacinas, portanto, trinta e cinco milhões, considerando a possibilidade de uma estimativa subdimensionada e as perdas de doses de vacina. Esse cálculo, segundo ele, não foi a tarefa mais difícil; a grande dificuldade era estabelecer quantas crianças havia em cada município brasileiro, para distribuir as vacinas adequadamente.

A estatística que se tinha era a do Censo de 1970, defasado em dez anos. Foram usadas estatísticas do Instituto Brasileiro de Geografia e Estatística (IBGE), algumas informações esporádicas de sistemas estatísticos dos estados e uma ou outra informação escassa do próprio sistema de saúde. Portanto, não se tinham dados para estimar a população de cada município, ainda menos dos municípios novos, municípios de fronteira agrícola, muito pobres, e já desenvolvendo um processo migratório para as cidades maiores, que, na década de 1970, foi intensificado. Assim, a distribuição de uma quantidade enorme de pessoas não estava prevista nas estatísticas disponíveis.

Para contornar essa situação, que apontava para o risco de faltar vacinas em determinados lugares e sobrar em outros, foi estabelecido um estoque nacional em Brasília, na Central de Medicamentos, articulado com uma base no Aeroporto de Brasília, bem como em todos os aeroportos - onde havia um delegado de saúde presente para, a qualquer problema, tomar a decisão necessária para resolvê-lo -, cada estado com seu estoque e um sistema de viaturas para rapidamente transferir vacinas de um lugar para outro. Cada secretaria de saúde tinha um estoque de emergência e cada região tinha um estoque adicional para remanejamento, ou seja, trazer vacinas do lugar que estava sobrando para o lugar em que estava faltando, como também para abastecer, de imediato, aqueles focos de maior pressão de demanda, que ocorreram muito mais nas capitais e nas grandes cidades. Sobre isso, Mozart Lima discorre, ressaltando a dificuldade de comunicação numa época pré-Internet:

Então a gente tinha que suprir essas unidades nesse esquema, usando todos os meios disponíveis: aviãozinho, automóvel, caminhão, tudo, tudo que fosse possivel [...]. Isso tudo feito com um sistema de telefonia ainda muito ruim, porque ainda não tinha Internet. Tivemos que colocar todo o sistema de telefonia à disposição do Ministério da Saúde, então era uma coisa muito importante, mas todo o Governo Federal estava harmonicamente condizente [...] um pedido de ligação telefônica do Ministério da Saúde tinha prioridade sobre todos. Naquela altura, você tinha que esperar horas, para falar com o município. E entrou aí uma rede sig- 
nificativa de instituições, como o Lions, o Rotary, [...] que fizeram também um papel de formiguinha, de comunicação. [...] A Associação Brasileira de Radioamadores colocou à disposição do Ministério, operando só para o Ministério nesse dia, com uma rede de comunicação fantástica ${ }^{20}$.

Mozart Lima prossegue no seu relato, emocionado, ao lembrar o primeiro dia nacional de vacinação:

Foi um dia realmente muito bonito na História da Saúde Pública. Via-se multidões nas ruas, multidões, as famílias foram realmente [aos postos de vacinação] e uma dificuldade muito grande de você conter, de você conduzir um processo de eliminação de dificuldades no $Q G$ do Ministério da Saúde em Brasília. Quartel-General mesmo, quartel para você tomar decisões de modo absolutamente imediato. Decisão de alugar um avião, decisão de fazer uma solicitação às Forças Armadas, quer dizer, tudo isso era muito dramático ${ }^{20}$.

Cristina Rocha também avalia positivamente os Dias Nacionais de Vacinação e assinala que renderam dividendos não só para a questão do controle da poliomielite mas também para a estruturação da Vigilância Epidemiológica, do Programa Nacional de Imunização, para a organização das equipes de saúde, para a prontidão das ações, para o trabalho com a comunidade, assim como para um aprimoramento do uso da mídia para as questões de saúde. Rocha, também emocionada, diz que viveu momentos de dúvida em relação ao projeto e que havia uma tensão muito grande, principalmente em face das resistências ao projeto. Ressalta que o grande ganho do projeto foi perceber que se pode trabalhar com a comunidade, que "a prestação de serviço não se dá só dentro das quatro paredes", que a comunidade respondeu muito positivamente. E acrescenta: "foi uma grande aprendizagem para a saúde pública”"25.

Em consequência aos Dias Nacionais de Vacinação, houve uma acentuada redução do número de casos da doença, passando de $1.290 \mathrm{ca}$ sos, em 1980, para 122, em 1981. No ano seguinte, observou-se o menor número de casos já registrados nacionalmente: 45 casos confirmados. A estratégia dos Dias Nacionais de Vacinação se repetiu a cada ano, e a cada ano os casos se aproximavam mais de zero.

O reconhecimento público dos Dias Nacionais de Vacinação consagrou definitivamente essa estratégia, que continua a ser implementada sistematicamente no Brasil. Em um processo de instabilidade política e descontinuidade administrativa que caracterizou, nessas duas décadas, o ce- nário institucional brasileiro com sérias repercussões para o setor saúde, essa estratégia pode ser considerada uma exceção. Adquiriu dimensão internacional ao ser recomendada pela Organização Pan-Americana da Saúde (Opas) como modelo, na ocasião da proposta de interrupção da transmissão do poliovírus selvagem na região das Américas.

\section{A campanha de erradicação da poliomielite no Brasil}

A possibilidade de erradicar uma doença ou seu vetor surgiu como conceito no final do século XIX, resultado do conhecimento científico acerca da causação e dos mecanismos de transmissão de várias doenças, bem como das medidas de prevenção e curativas. A partir daí, várias definições foram dadas ao termo erradicação, ao longo do tempo.

Verani ${ }^{26}$, em sua dissertação de mestrado, discute o conceito de erradicação e apresenta a posição de alguns sanitaristas envolvidos com a questão. Segundo Verani, Galdston considera a erradicação como o equilíbrio ecológico entre o homem, o agente e o meio ambiente, fazendo diminuir a incidência a um ponto em que não seria prejudicada nenhuma das partes dessa interação. Já Cockburn defende que o termo deveria ser aplicado a doenças cujo agente patógeno teria sido extinto em todo o mundo, e reforça que se há necessidade de medidas para evitar o retorno da doença, então a situação é de controle, não de erradicação.

Andrews e Langmuir ${ }^{27}$ fazem uma diferenciação entre controle e erradicação, dizendo que controle de uma doença é a sua redução proposital a níveis relativamente baixos de ocorrência, sem o seu desaparecimento definitivo; erradicação é uma continuada ausência de transmissão da doença, dentro de uma determinada área. Autores russos contemporizam e conceituam a erradicação como uma redução na incidência da doença a tal ponto que ela deixaria de ser um problema de saúde pública ${ }^{26}$.

A $1^{\text {a }}$ Conferência Internacional sobre Erradicação de Doenças, realizada em 1980, elaborou o conceito moderno de erradicação: Erradicação de uma infecção significa que a infecção desapareceu de todos os países do mundo, porque a transmissão do organismo causador cessou de uma maneira irreversivel ${ }^{28}$.

Evans $^{29}$ afirma que a erradicação global verdadeira da maioria das doenças notificáveis é mais 
mito do que realidade. Yekutiel ${ }^{30}$, por seu lado, ressalta a necessidade de algumas precondições para o empreendimento de um programa de erradicação, dentre elas a existência de uma vacina de baixo custo, facilidade de diagnóstico da doença, reconhecida importância da doença, capacidade financeira e administrativa adequada e recursos de serviços de saúde.

As precondições pautadas por Yekutiel ${ }^{30}$ não estavam colocadas para nenhuma doença, no início da década de 1980, segundo Evans, que considerava a erradicação global da varíola como uma conquista gloriosa, mas não aplicável para outra doença, no que foi apoiado por vários especialistas que participaram do programa de erradicação da varíola.

Frank Fenner, um virologista renomado e líder da equipe de avaliação da varíola, segundo relato de Evans $^{29}$, disse em uma conferência sobre erradicação que, se o encontro era para definir outros candidatos à erradicação global imediata, deveriam "fazer as malas e ir para casa", pois não havia outra doença com critérios biológicos e socioeconômicos adequados (p. 204 ${ }^{29}$.

Em meio a esse debate, Ciro de Quadros ${ }^{1}$, então diretor de Vacinas da Opas, tão logo constatou o impacto dos Dias Nacionais de Vacinação na incidência da poliomielite no Brasil, começou a investigar as possibilidades de lançar um programa de pólio nas Américas. Procurou Donald Henderson, o qual dirigiu o Programa Mundial de Erradicação da Varíola, da Organização Mundial da Saúda (OMS), de 1966 a 1977, que considerou a ideia impossível pelo fato de a poliomielite apresentar dois problemas importantes: o primeiro diz respeito às dificuldades de detecção da presença do poliovírus numa dada região, porque um caso de paralisia flácida aguda devido à poliomielite representa somente $1 \%$ dos casos; o segundo problema é pelo fato de a vacina contra pólio não ser termoestável como a da varíola ${ }^{31}$.

Entretanto, em fins de 1984, James Grant, então diretor do United Nations Children Fund (Unicef), que partir de 1982 investiu em uma intensa campanha para combater o que chamou de "a emergência silenciosa mundial", que seriam as mortes de milhões de crianças por doenças facilmente preveníveis, procurou o diretor da Opas, Carlyle Guerra de Macedo, para propor um programa de vacinação nas Américas, já que o continente estava melhor estruturado ${ }^{1}$. Essa negociação resultou na decisão de erradicar uma doença imunoprevenível para dar credibilidade à vacina e mobilizar todos os países. A poliomielite foi a doença escolhida, na medida em que alguns países já apresentavam experiências de sucesso no seu controle.

Evans $^{29}$ já havia dito que um dos fatores que favoreceriam o controle de uma doença é "uma força política suficiente que levará o programa até uma conclusão bem sucedida" (p. 199). E foi assim que, com "força política suficiente", o diretor da Opas anunciou a meta de interromper a transmissão do poliovírus selvagem das Américas até 1990, com o apoio do Unicef, da United States Agency for International Development (USAID), do Banco Interamericano de Desenvolvimento (BID) e do Rotary Internacional. Na XXXI Reunião do Conselho Diretivo da Opas, realizada em setembro de 1985 , os países membros aprovaram essa iniciativa e se comprometeram com ela. No Brasil, a interrupção da transmissão do poliovírus selvagem inseriu-se no programa de prioridades sociais da Nova República, em 1986.

As agências internacionais tiveram um papel fundamental no êxito da proposta de erradicação da transmissão do poliovírus selvagem nas Américas. O Rotary Internacional, por exemplo, instituiu, em 1985, o Programa Pólio Plus, com o propósito de colaborar na imunização de todas as crianças do mundo até 2005 . Além de ser provavelmente o principal contribuinte não governamental nos esforços globais para a erradicação da poliomielite - calcula-se que até 2005 sua contribuição foi de aproximadamente meio bilhão de dólares -, centenas de milhares de seus voluntários no mundo todo atuaram na entrega de vacinas, na mobilização social e no planejamento logístico. Esses esforços voluntários dos rotarianos, divulgados sistematicamente em sua revista Brasil Rotário, foram extremamente valiosos na erradicação da pólio nos países das Américas.

No Brasil, em 1986, foi criado o Grupo de Trabalho para a Erradicação da Pólio (GT-Pólio), com o objetivo de dar maior eficiência à cobertura de vacinação, fazer um acompanhamento mais refinado do comportamento epidemiológico da poliomielite e desencadear as medidas de controle necessárias, supervisionadas e avaliadas adequadamente. O Plano de Ação para a Erradicação da Poliomielite no Brasil foi aprovado pela Resolução Ciplan no 4, de 6 de fevereiro de 1986.

O programa de erradicação da poliomielite no país assentava-se em dois eixos básicos: a intensificação da imunização, alcançando e mantendo altas coberturas vacinais (>90\%) de forma homogênea, e o estabelecimento ou ampliação das atividades de vigilância epidemiológica da doença 
paralítica e controle de surtos (bloqueio). A investigação de casos levou o programa a rever e modificar seus conceitos e métodos de vigilância, à medida que o conhecimento sobre a doença se ampliava, tanto nos aspectos clínicos como nos epidemiológicos. Uma das medidas foi criar comissões de avaliação clínica constituída por neurologistas, para definir um caso de pólio na ausência de amostras laboratoriais de fezes.

Com o objetivo de esclarecer as possíveis controvérsias no diagnóstico da doença, em 1990 o Grupo Técnico Assessor para a Erradicação da Pólio elaborou as seguintes definições: "poliomielite confirmada" seria a enfermidade paralítica aguda associada ao isolamento de poliovírus selvagem; "poliomielite vacinal" seria a enfermidade paralítica aguda associada ao isolamento de vírus vacinal em pessoa que tenha recebido a vacina oral trinta dias antes da manifestação da doença e que não tenha sido exposta à vacina oral depois da manifestação dos sintomas; e a "poliomielite compatível" seria a enfermidade paralítica aguda, com paralisia residual aos sessenta e cinco dias, ou morte. Recomendou ainda que qualquer área em que houvesse um caso favorável de poliomielite deveria ser objeto de uma ação de bloqueio e que uma área extensa em torno do caso fosse completamente vacinada/revacinada ${ }^{32}$.

Em março de 1989, foi notificado o que seria o último isolamento do poliovírus selvagem no país, no município de Souza, na Paraíba. Nesse ano, foram realizadas 302 operações limpeza em municípios brasileiros, sendo 141 na região Nordeste, indicadas, principalmente, com base no seguinte critério: casos confirmados e/ou isolamento de poliovírus selvagem, no período de 1987 e 1989. Durante essas operações limpeza, foram vacinadas mais de 1,4 milhão de crianças menores de cinco anos. De 1990 até 1993, foram realizadas 154 operações limpeza em municípios de ocorrência de casos de PFA clinicamente compatíveis com pólio, com a finalidade de revisar os casos confirmados e, posteriormente, os poliocompatíveis, assim como aqueles nos quais havia dúvida quanto à classificação final. Para isso, em agosto de 1989, foi criada a Comissão Nacional de Revisão de Casos de Poliomielite ${ }^{32}$.

A partir de 1990, embora mantendo as estratégias utilizadas até então para alcançar a erradicação da poliomielite, o Brasil direcionou o programa para o cumprimento dos critérios estabelecidos pela Comissão Internacional de Certificação da Erradicação da Poliomielite. E, em 1994, o Brasil recebeu a Certificação da Erradicação da Poliomielite.

\section{Comentários finais}

A política de controle da poliomielite tornou-se possível a partir da segunda metade do século $\mathrm{XX}$, com a descoberta de vacinas eficazes contra a doença, o desenvolvimento de técnicas laboratoriais para diagnóstico e novos procedimentos de vigilância epidemiológica.

As campanhas nacionais de vacinação contra a poliomielite, no Brasil, iniciaram-se na década de 1960. Inicialmente de alcance restrito, ocorrendo somente em alguns estados brasileiros, atingiu sua efetividade com os Dias Nacionais de Vacinação, proposto pelo Ministério da Saúde em 1980. Nesse processo, várias negociações foram necessárias junto aos estados, mas principalmente houve uma decisão política no âmbito do governo central.

O resultado positivo dos Dias Nacionais de Vacinação chamou a atenção de organizações internacionais de saúde e levou à proposta de erradicação da doença nas Américas. Esse processo novamente resultou em negociações políticas e técnicas. No entanto, com uma força política suficiente para levar o programa até uma conclusão bem-sucedida, o diretor da Opas anunciou a meta de interromper a transmissão do poliovírus selvagem das Américas até 1990, com o apoio do Unicef, USAID, BID e Rotary Internacional. Na XXXI Reunião do Conselho Diretivo da Opas, realizada em setembro de 1985, os países membros aprovaram essa iniciativa e se comprometeram com ela. No Brasil, a interrupção da transmissão do poliovírus selvagem inseriuse no programa de prioridades sociais da Nova República, em 1986.

Apesar de o conceito de erradicação, estabelecido na década de 1980, implicar uma abrangência mundial, as controvérsias no uso do conceito persistiram, e a proposta de interromper a transmissão do poliovírus selvagem nas Américas, mesmo sendo de abrangência regional, passou a ser considerada um programa de erradicação.

A política de erradicação da poliomielite nas Américas foi uma ação bem-sucedida, que congregou vários setores da sociedade civil capitaneada pelo setor saúde, eliminando do continente americano uma doença que produzia incapacidade física permanente. 


\section{Referências}

1. Quadros C. Acervo de depoimentos orais, memória da poliomielite. Rio de Janeiro: Casa de Oswaldo Cruz/ DAD/Arquivo Sonoro; 2001.

2. Campos AL. A história da poliomielite no Brasil antes da vacina: modelos, epidemias e dilemas. In: Nascimento DR, organizadora. A história da poliomielite. Rio de Janeiro: Garamond; 2010. p. 15-52.

3. Maranhão ESP. A história das vacinas contra a poliomielite. In: Nascimento DR, organizadora. A história da poliomielite. Rio de Janeiro: Garamond; 2010. p. 53-84.

4. Bodian D. Differention of types of poliomyelitis viruses: reinfection experiments in monkeys (second attacks). Am J Hyg 1949; 49:200.

5. Bodian D. A reconsideration of the pathogenesis of poliomyelitis. Am J Hyg 1952; 55:414.

6. Moulin AM, organizadora. L'aventure de la vaccination. Paris: Fayard; 1996.

7. Robbins FC. The history of polio vaccine development. Philadelphia, PA: WB Saunders Company; 1999.

8. Koprowski H, Ploktin S. Histoire alternative du vaccine oral. In: Moulin AM, organizadora. L'aventure de la vaccination. Paris: Fayard; 1996.

9. Schatzmayr HG, Filippis AMB, Friedrich F, Leal MLF. Erradicação da poliomielite no Brasil: a contribuição da Fundação Oswaldo Cruz. História, Ciências, Saúde - Manguinhos 2002; 9(1):11-24.

10. Thacker SB, Berkelman RL. History of Public Health Surveillance. In: Halperin W, Baker EL, Monson RR, editors. Public Health Surveillance. New York: Van Nostrand Reinhold; 1992. p. 1-15.

11. Campos ALV, Nascimento DR, Maranhão ESP. A história da poliomielite no Brasil e seu controle por imunização. História, Ciências, Saúde - Manguinhos 2003; 10(Supl.2):573-600.

12. O Estado de S. Paulo 1960; 27 jul. p. 9.

13. Correio da Manhã 1961; 8 abr. p. 3 .

14. Correio da Manhã 1961; $1^{\circ}$ set. p. 2.

15. Correio da Manhã 1961; 6 out. p. 2.

16. Nascimento DR, Maranhão ESP. Uma gota, duas doses: criança sadia, sem paralisia. In: Nascimento DR, Carvalho DM, organizadores. Uma história brasileira das doenças. Brasília: Paralelo 14; 2004. p. 229-241.

17. Risi Junior JB. Acervo de depoimentos orais, memória da poliomielite. Rio de Janeiro: Casa de Oswaldo Cruz/DAD/Arquivo Sonoro; 2000.

18. Rogers N. Dirt and disease: pólio before FDR. New Brunswick, NJ: Rutgers University Press; 1996.
19. Brasil. Ministério da Saúde. Programa Nacional de Imunizações - 20 anos. Brasília: Ministério da Saúde; 1993.

20. Lima MA. Acervo de depoimentos orais, memória da poliomielite. Brasília: Casa de Oswaldo Cruz/DAD/ Arquivo Sonoro; 2002.

21. Becker R. Acervo de depoimentos orais, memória da poliomielite. Brasília: Casa de Oswaldo Cruz/DAD/ Arquivo Sonoro; 2002.

22. Risi Junior JB. Considerações sobre a consultoria prestada pelo doutor Sabin ao Ministério da Saúde: esclarecimentos necessários em face das repercussões de seu afastamento [comunicação pessoal]. Brasília, 18 abr. 1980.

23. O Globo 1980; 28 mar. p. 14.

24. Jornal do Brasil 1980; 22 maio. $1^{\circ}$ Caderno.

25. Rocha CMV. Acervo de depoimentos orais, memória da poliomielite. Maceió: Casa de Oswaldo Cruz/ DAD/Arquivo Sonoro; 2002.

26. Verani JFS. A vigilância epidemiológica na erradicação de doenças: o caso da varíola e da poliomielite [dissertação]. Rio de Janeiro: Escola Nacional de Saúde Pública Sergio Arouca; 1991.

27. Andrews JM, Langmuir AD. The philosophy of disease eradication. Journal of Public Health 1963; 53(1):1-6.

28. Hinman AR. Potencial candidates for eradication. Reviews of Infectious Diseases 1982; 4(5):12.

29. Evans A. The eradication of communicable diseases: myth or reality? American Journal of Epidemiology 1985; 122(2):199-207.

30. Yekutiel P. Erradication of infectious diseases: a critical study. New York: Karger; 1980.

31. Henderson D. Como é que a variola mostrou o caminho: a saúde no mundo. Brasília: Organização Mundial da Saúde; 1989. p. 19-21.

32. Brasil. Ministério da Saúde. Bases técnicas para a erradicação da transmissão autóctone da poliomielite. Brasília: Centro de Documentação do Ministério da Saúde; 1988.

Artigo apresentado em 18/4/2010

Aprovado em 14/6/2010

Versão final apresentada em 11/7/2010 